\title{
Galina Mladenova* \\ MARKETING STRATEGY OF APPAREL AND TEXTILE CLUSTER IN SOUTHWEST REGION OF BULGARIA ${ }^{1}$
}

\begin{abstract}
This paper provides an analysis of marketing activities and marketing organization of the Southwest apparel and textile cluster in Bulgaria. The first section of the paper gives an overview of the organization and functioning of the cluster. The second section focuses on the cluster marketing, analyzing its success to date and identifying the challenges it faces going forward.

The purpose of the research report is to present and to analyze the marketing strategy of "Inter Moda Trading Cluster" in the Southwest region of Bulgaria.

The sources of data which have been used in the research process are: official trade publications, cluster's publications (internet site, bulletins, brochures, newsletters etc.), internal documents, depth interviews that were carried out with cluster's top managers and the Chair of the Commercial Chamber in the city of Kyustendil.
\end{abstract}

Keywords: cluster marketing, apparel and textile cluster; Bulgaria.

\section{1. "INTER MODA TRADING CLUSTER": IT'S GOALS, ORGANIZATION AND FUNCTIONS}

The apparel and textile sector today has to face major challenges that are forcing it to redefine its role. Unrelenting pressure from countries with lower labor costs is forcing stakeholders to turn increasingly towards niche markets and to join their efforts.

There are several reasons why southwest apparel cluster "Inter Moda Trading" can be considered as a competitive cluster. Firstly, it is the significance of this sector within the manufacturing industry of the Southwest region in Bulgaria (NUTS - 2) - it is one of the largest manufacturing sector in the region. It should also be noted that this region has a largest concentration of jobs in textile and clothing in Bulgaria. According to the European Cluster Observatory rating the

\footnotetext{
${ }^{*}$ University of National and World Economy in Sofia, Faculty of Management and Administration.

${ }^{1}$ This article was prepared as part of the $7^{\text {th }}$ Framework Programme FP7-PEOPLE-2011-IRSES Project No. 295050 FOLPSEC - Functioning of the local production systems in the conditions of economic crisis (comparative analysis and benchmarking for the EU and beyond).
} 
apparel and textile Southwest regional cluster in Bulgaria received three stars ${ }^{2}$ and can be assessed as a strong one (Table 1).

Table 1

European Cluster Observatory: Star rating of Southwest region clusters in Bulgaria

\begin{tabular}{|l|c|c|}
\hline \multicolumn{2}{|c|}{ Southwest planning region (Yugozapaden) } \\
\hline \multicolumn{1}{|c|}{ Industry } & Stars & Employees \\
\hline Apparel & $\star \star \star$ & 29391 \\
\hline Agricultural products & $\star \star$ & 23431 \\
\hline Biotech & $\star \star$ & 1909 \\
\hline Farming and animal husbandry & $\star \star$ & 21386 \\
\hline Footwear & $\star \star$ & 7248 \\
\hline Textiles & $\star \star$ & 19184 \\
\hline Tobacco & $\star \star$ & 41915 \\
\hline Construction & $\star$ & 23464 \\
\hline Distribution & $\star$ & 495 \\
\hline
\end{tabular}

Source: Star Clusters in Bulgaria (2011), Center for Strategy and Competitiveness, CSC Stockholm School of Economics, April 2011. www.clusterobservatory.eu/common/galeries/downloads/ Star_cluster_Bulgaria.pdf.

${ }^{2}$ www.clusterobservatory.eu/common/galeries/downloads/Star_cluster_Bulgaria.pdf. Star ranking refers to the following criteria:

- Size shows whether a cluster is in the top $10 \%$ of all clusters in Europe within the same cluster category in terms of the number of employees.

- Specialization: if a region is more specialized in a specific cluster category than the overall economy across all regions, this is likely to be an indication that the economic effects of the regional cluster have been strong enough to attract related economic activity from other regions to this location, and that spill-overs and linkages will be stronger. The specialization measure compares the proportion of employment in a cluster category in a region over the total employment in the same region, to the proportion of total European employment in that cluster category over total European employment. The measure needs to be at least 2 to receive a star.

-Focus: if a cluster accounts for a larger share of a region's overall employment, it is more likely that spill-over effects and linkages will actually occur instead of being drowned in the economic interaction of other parts of the regional economy. The focus measure shows the extent to which the regional economy is focused upon the industries comprising the cluster category and relates employment in the cluster to total employment in the region. The top $10 \%$ of clusters which account for the largest proportion of their region's total employment receive a star. 
"Inter Moda Trading Cluster" is a newly established entity and it was entered into the Commercial Register at the Bulgarian Registry Agency on 30 March 2011. The cluster was developed with the financial support of the Operational Program Development of Competitiveness of the Bulgarian Economy 2007-2013, co-financed by the European Union through the European Regional Development Fund and the national budget of the Republic of Bulgaria.

The main cluster's objective is to enhance the competitiveness and increase export opportunities of SMEs in the textile and clothing industries of the Southwest region, by integrating them in a cluster network in response to the requirements and pressure from the European and world markets. Main cluster activities $^{3}$ include:

- Organizing cluster's administrative structure and resource provision,

- Development of general and marketing strategy for the cluster's growth,

- Participation in apparel and clothing international fairs in the EU Member States,

- Organizing and taking part in business meetings with the EU member states to establish contacts and exchange experiences and best practices,

- Developing product catalogue for cluster members' and its publication,

- Publication and distribution of a monthly electronic newsletter,

- Running and managing active advertising and information campaigns to promote the cluster, etc.

The expected result is to strengthen cluster members' position on both domestic and international markets through the exchange of experiences and best practices, better recognition, popularity and image of the cluster leading to attracting new members as well as potential customers and partners.

The cluster was established based on regional and industry criteria. It comprises garment manufacturers in the Southwest region of the country along with companies providing services to textile and clothing industry.

The "Inter Moda Trading Cluster" members are small and medium-sized companies (private and cooperative businesses), localized in Sofia, Kyustendil, Dupnitsa, Blagoevgrad and Sandanski. All of the cluster participants have united to work towards the promotion of competitiveness, productivity and effectiveness of the regional industry.

Cluster operates through a number of regionally connected similar, interrelated or complementary businesses with active channels for business relationships and communication, with common facilities, labor markets and services, sharing growth opportunities or facing common threats (Figure 1). Inter-linkages between cluster members are based on the principle of cooperation with the assumption of competition on the internal market and partnership on foreign markets (cooperation and competition). The aim is to establish

\footnotetext{
${ }^{3}$ Cluster internal documents.
} 
rules for cooperation, under which enterprises remain fully independent, but become more competitive by joining their resources, capabilities and potential, in order to enhance their export opportunities according to the market requirements.

The cluster members are:

- Piros $\mathrm{Ltd}^{4}$, Sandanski - long experienced garment manufacturer specialized in the production of knitwear. Piros Ltd offers an extensive range of knitwear ready to wear products for men, women and children. It includes blouses, gowns, shirts, jumpers, blazers, dresses.

- Nov Svjat Cooperative ${ }^{5}$, Blagoevgrad - their main activity consist in producing ladies' ready-to-wear apparel. It offers a variety of women's garments in casual and official elegant business style including suits, skirts, trousers, blouses, dresses, ladies outerwear, such as coats, jackets and raincoats.

- Nitex Ltd ${ }^{6}$, Sofia - the company specializes in the production of apparel auxiliary materials as woven and knitted elastic bands, tapes, cords, satin ribbons, decoration ribbons and other haberdashery products.

- Vital Ltd ${ }^{7}, \mathrm{Kyustendil} \mathrm{-} \mathrm{specialized} \mathrm{in} \mathrm{men's} \mathrm{and} \mathrm{women's} \mathrm{trousers} \mathrm{man-}$ ufacturing. Product range includes pants in casual and timeless classic styles, bermudas, skirts and uniforms.

- Boda Stil Ltd ${ }^{8}$, Dupnitza - specialized in manufacturing of upper outerwear for men and women. The product range includes a variety of sport and casual jackets and coats.

- Martex2 $\operatorname{Ltd}^{9}$, Sofia - highly specialized in manufacturing of men's and women's upper outerwear. Their product range includes a variety of jackets and coats in casual and elegant styles. Martex 2 is a highly specialized producer of down jackets.

- YAKI-91 Ltd ${ }^{10}$, Sofia - its main field of activity includes embroidery, sublimation termotransfer printing and a broad range of variety of clothes decorations.

- Silver Day $\operatorname{Ltd}^{11}$, Samokov - its main business activity is hand and machine knitting. Silver Day offers unique knitting patterns made from natural fibers as linen, cotton, silk and wool.

\footnotetext{
${ }^{4}$ www.piros-bg.com.

${ }^{5}$ www.novsvjat.com.

${ }^{6}$ www.nitex-bg.com.

${ }^{7}$ www.vitalbg.com.

${ }^{8}$ www.boda-stil.vips.bg.

${ }^{9}$ www.companylist.org.

${ }^{10}$ www.yaki91.com.

${ }^{11}$ www.fashion.bg/firm/silver.day/2013.
} 
- TeA Textil Andonovi Ltd ${ }^{12}$, Dupnitza - the company is long experienced manufacturer of knitted underwear for men, women and children and is specialized in producing children's underwear.

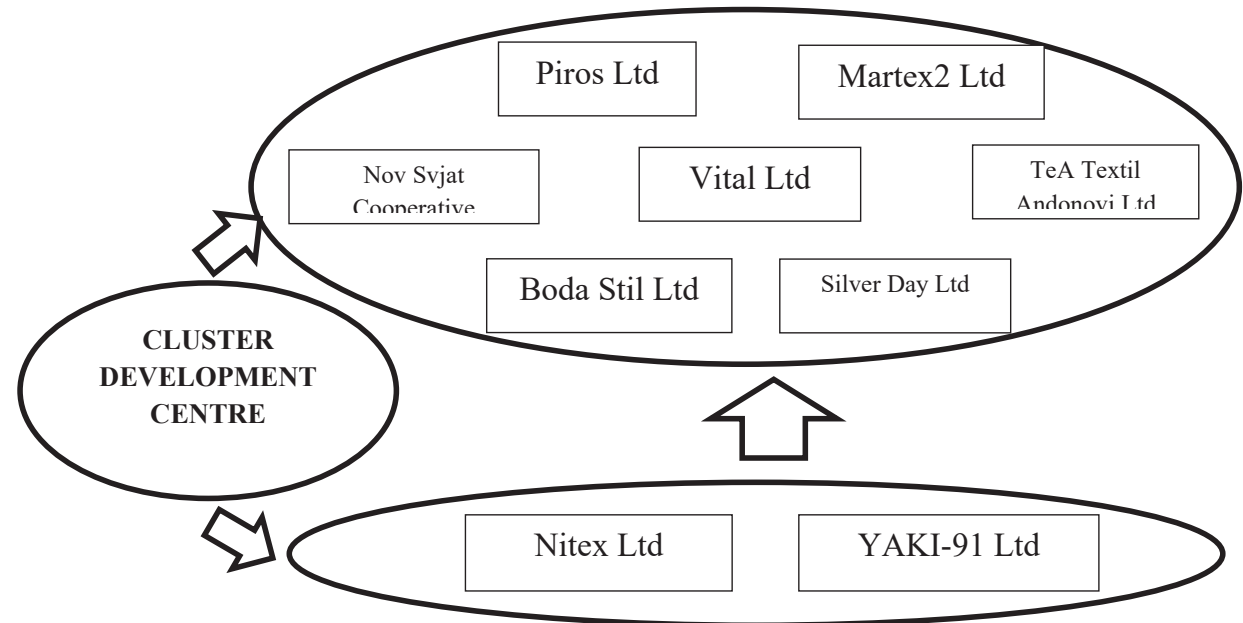

Figure 1. Inter Moda Trade Cluster's relationships

Source: The figure developed by the author.

Cluster members cooperate in the following areas:

- agency services - include support in communication with foreign clients and contractors in order to enter new markets,

- training and consulting services, aimed at enhanced productivity and efficiency of the members and the cluster as whole,

- research services, e.g. own brand registration, market research, information about particular suppliers, etc.,

- up-to-date information about new developments in textile and clothing sector (machinery, textile materials etc.),

- international activities: support in international contacts on cluster and member-companies level; organization of visits and trips abroad to exchange experiences; arrangement of member-companies' participation in national and international exhibitions; developing common international marketing strategies.

\footnotetext{
${ }^{12}$ www.teatextile.com.
} 


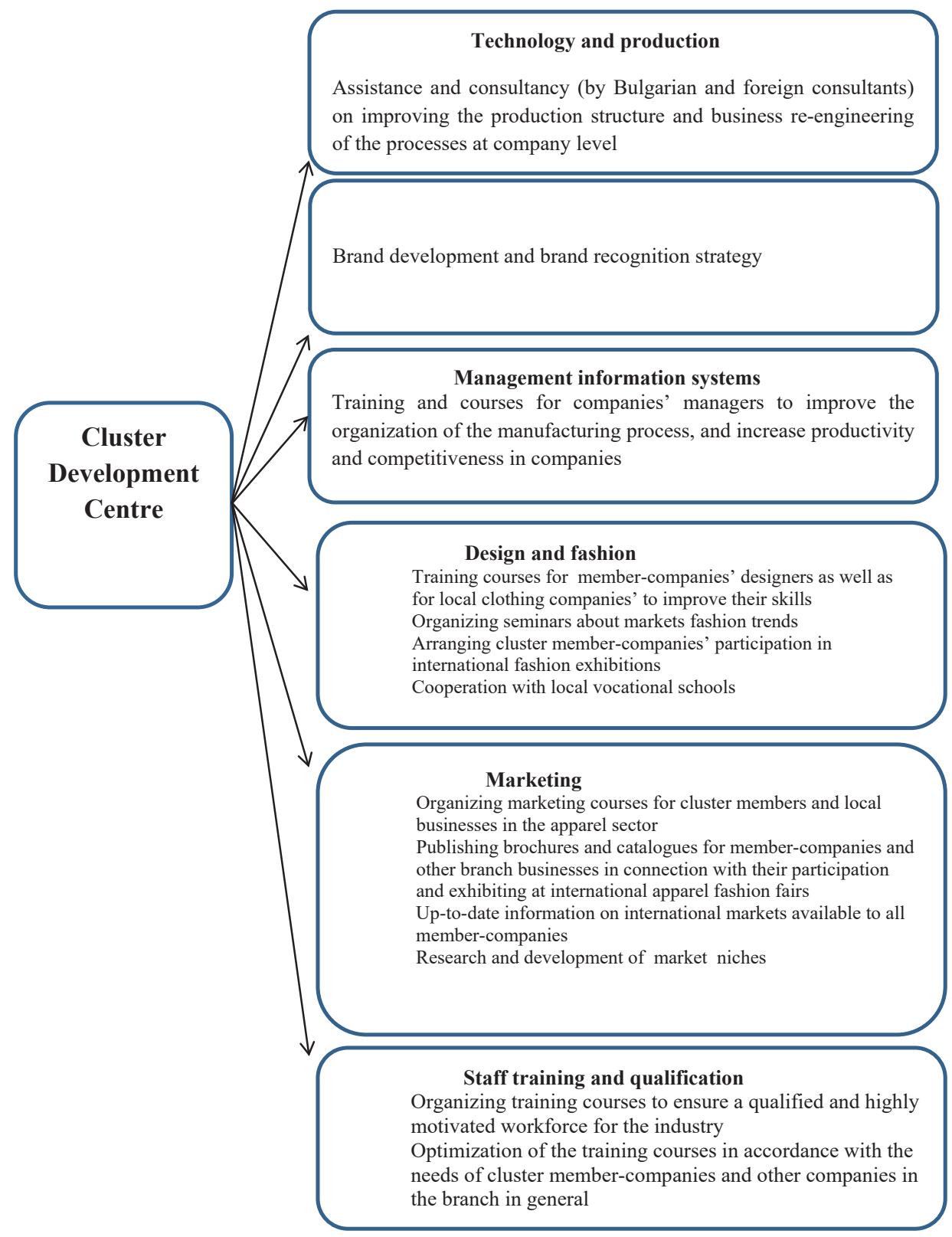

Figure 2. Cluster Development Centre - functions

Source: Cluster internal documents.

As a result of cooperation Cluster Development Centre was founded. It operates in areas described in Figure 2. 


\section{CLUSTER MARKETING STRATEGY ANALYSIS: UP-TO-DATE SUCCESS AND CHALLENGES}

Cluster marketing can be seen as a social process, directed at satisfying customer, as well as regional communities and cluster members, needs based on the cooperation of marketing resources and activities, which results in achieving market competitiveness and overall functional efficiency for the cluster and its individual members.

We could define cluster marketing as a systematic process of purposefully combining separate marketing activities and resources within the cluster to achieve organizational goals of each cluster member through more effective participation in the competitive marketing process and creation of competitive advantages, based on greater efficiency and innovation.

As a management process, cluster marketing is a complex interaction, involving various levels and degrees of commitment between organizations including: collaboration in the development of a common marketing strategy of the cluster; collaboration in the development of individual marketing strategies of members in the context of the cluster marketing strategy; cooperation in coordinating marketing strategies of the members in the cluster.

Marketing advantages for the cluster can be achieved through the synergy in the area of marketing research, developing new markets, providing access to exsisting and new markets, development of new products, development and co-use of marketing channels, etc.

As a result of the combined strength, through common marketing efforts, competitive advantage of relatively small players- members of the cluster is "enhanced". It is ensured by providing common services to existing and new markets. It allows for the survival of start-ups and small firms and for the long-term strengthening of their positions on the market. Marketing enables small and medium-sized companies in the cluster to overcome resource, management and time-related limitations and to take advantage of the integrated strength of the cluster for penetration and development on the market. As a rule, each individual participant has limited material, financial, human and information resources, and the implementation of individual marketing activity is relatively inefficient. Along with this, such "collective" strength allows the "survival" mindset to be transformed into proactive strategic thinking and behavior, i.e. to improve company management.

"Inter Moda Trading Cluster" is a relatively new cluster, and until now within it there is not any special structure is responsible for governing the marketing activities. At this initial stage of its development, the cluster is focused on training its own employees to enhance their marketing and sales knowledge and skills. It is important because the companies-members of the cluster are small and do not 
have their own marketing departments. This basically means that their market performance is almost totally dependent on the cluster. Chief expert, responsible for business development of the cluster as well as for the monitoring and controlling of business processes in the companies also coordinates marketing. The main functions carried out by the management staff include ${ }^{13}$ :

- continuous market research and analysis in order to collect market information for strategic and operational decisions,

- identification of different market segments and planning relevant marketing activities,

- hiring consultancy services in finance, operational management, marketing and design;

- registering cluster trade mark,

- establishing cooperation schemes with universities, schools and others to offer courses focused on the needs of the cluster,

- organizing trade shows,

- updating cluster website, catalogues, brochures and other promotional materials, with particular attention paid to advertising in points of sales.

"Inter Moda Trading Cluster" has developed a cluster marketing strategy, which main goal is to increase market share in the domestic market and to enter new markets. In accordance to this goal, measures and activities concerning the development of cluster product mix are planned. There is also a set of efforts aimed at the achievement of competitive price-quality ratio, determination of appropriate distribution channels and implementation of a flexible and competitive pricing policy.

One of the main cluster objectives at the initial stage of development is to create its popularity and recognition. Marketing activities for promotion and development of the cluster include:

- Organizing press conferences, workshops; printing ads, brochures and fashion catalogues. Also, the management of the cluster organized a series of meetings with sectorial organizations from France and similar clusters from Italy. These meetings enable the exchange of good business and marketing practices. The cluster has established close relationships with other apparel and textile clusters of neighboring countries (the cluster localized in Stip, Macedonia) too.

- Participation in international fashion fairs. The apparel sector can count on a number of showcase events to present its products. According to the cluster marketing strategy, the cluster has been presented at some prestigious international exhibitions (Zoom By Fatex, Paris, France; Ready to show, Milan, Italy; ModaIn, Florence, Italy; London Expo Garments, London, England; Source IT, Frankfurt, Germany; CPM, Moscow, Russia). As a result of this, more than 100 contacts with companies producing fashion brands have been established.

\footnotetext{
${ }^{13}$ Cluster internal documents.
} 
- Publishing a monthly newsletter containing useful information about textile and apparel industry which is sent to more than 500 industrial companies.

The marketing strategy of "Inter Moda Trading Cluster" is focused on three strategic market levels:

- EU market, as a priority,

- regional markets (markets of neighboring countries),

- domestic market.

The clothing market is characterized by a surge in the number of brand names or labels, which consumers see as bringing more value to products. According to its marketing strategy, "Inter Moda Trading Cluster" is also in the process of registering its collective trade mark - LABAS. The chosen cluster brand model of marketing has undisputable advantages. It assumes that at the highest level there should be differentiated joint activities, aimed at developing and consolidating a single cluster brand, while at the middle level - the activities related to the management of corporate brands and at the lowest level - product brands. It should be emphasized that the three levels are interrelated. The value of the cluster brand grows when there are strong corporate and product brands and vice versa - a strong cluster brand has a positive impact on corporate and product brands.

The main challenge could be how to convert the trade mark LABAS into a brand. The brand needs to be backed by major advertising and promotional campaigns. The lack of finances and tight advertising budget could be a real threat to achieving branding goals.

The case analysis here focuses on some qualitative aspects that describe marketing process in the "Inter Moda Trading Cluster". A limitation of this case study consist in the fact, that the analysis does not deal with what the cluster has achieved, which certainly is an important and complex element to be evaluated. In a cluster such as the one analyzed here, performance is relevant from various points of view. The achievements of the "Inter Moda Trading Cluster" are noticeable at the level of the individual organizations within the cluster, and they can be identify at the cluster level as an organizational unit as well.

\section{REFERENCES}

Altenburg T., Meyer-Stamer J. (1999), How to promote clusters: policy experiences from Latin America, "World Development", vol. 27, no. 9, p. 1693-713.

Arikan A. (2009), Interfirm knowledge exchanges and the knowledge creation capability of clusters, "Academy of Management Review", vol. 34, no. 4, p. 658-676.

Bell S., Tracey P., Heide J. (2009), The organization of regional clusters, “Academy of Management Review", vol. 34, no. 4, p. 623-642.

Brown P., McNaughton R., Bell J. (2010), Marketing externalities in industrial clusters: a literature review and evidence from the Christchurch New Zealand electronics cluster, "Journal of International Entrepreneurship", vol. 8, no. 2, p. 168-181. 
Carson D., Gilmore A., Rocks S. (2004), SME marketing networking: a strategic approach, "Strategic Change", vol. 1, no. 7, p. 369-382.

Chimhanzi J. (2004), The impact of marketing/HR interactions on marketing strategy, "European Journal of Marketing", vol. 38, no. 1/2, p. 73-98.

Felzensztein C., Gimmon E. (2012), Clusters or un-clustered industries? Where inter-firm marketing cooperation matters, "Journal of Business \& Industrial Marketing", no. 27/5, p. 392-402.

Felzensztein C., Gimmon E., Carter S. (2010), Geographical co-location, social networks and inter-firm marketing cooperation: the case of the salmon industry, "Long Range Planning", vol. 43 , no. 5-6, p. 675-690.

Guercini S., Woodside A.G. (2012), A strategic supply chain approach: consortium marketing in the Italian leatherwear industry, "Marketing Intelligence \& Planning", vol. 30, no. 7, p. 700-716.

Mladenova G. (2014), A marketing approach to the local production systems management, [in:] A. S. Novoselov, V.E. Selivestrov (eds.), Local production systems and regional economic development, Novosibirsk-Sofia-Lodz-Ternopil, p. 22-34.

Morgan R., Hunt S. (1994), Commitment-trust theory of relationships marketing, "Journal of Marketing", vol. 57, July, p. 20-38.

Porter M. (2000), Clusters and the new economics of competition, "Harvard Business Review", vol. 76, no. 6, p. 77-90.

Tu H. (2011), Cluster Marketing Models and Strategies: The Implications Thereof in the Chinese High-Tech Industry, "The International Journal of China Marketing", vol. 1(2), p. 34-44. 